Case Report

\title{
Acute alloxan toxicity causes granulomatous tubulointerstitial nephritis with severe mineralization
}

\author{
Lianshan Zhang1, Yui Terayama², Taiki Nishimoto², Yasushi Kodama ${ }^{3}$, and Kiyokazu Ozaki²* \\ ${ }^{1}$ Department of Pathology, Hebei Medical University, 361 Zhongshan East Road, Shijiazhuang 050017, China \\ 2 Laboratory of Pathology, Faculty of Pharmaceutical Sciences, Setsunan University, 45-1 Nagaotoge-cho, Hirakata, Osaka 573-0101, \\ Japan \\ ${ }^{3}$ Laboratory of Clinicopathological Therapeutics, Faculty of Pharmaceutical Sciences, Hiroshima International University, 5-1-1 \\ Hirokoshinkai, Kure, Hiroshima 737-0112, Japan
}

\begin{abstract}
Alloxan had been recognized as having a direct nephrotoxic effect different from its diabetogenic action. We encountered previously unreported granulomatous tubulointerstitial nephritis with severe luminal and interstitial mineralization in one diabetic rat after one week of alloxan administration. Histopathologically, many dilated and occluded proximal and distal tubules were segmentally observed in the cortex and outer medulla. The tubular lumen contained minerals and cell debris. Tubular epithelial cells were degenerated and piled up, and they protruded into the lumen, where they enveloped minerals. Mineralization was observed mainly in the tubular lumen, and to some extent in the subepithelium and interstitium. The mineralization beneath the tubular epithelium was often continuous from the subepithelium to the interstitium. In these lesions, the tubular basement membrane was disrupted by mineralization, and a granuloma with multinuclear foreign-body giant cells was formed in the interstitial areas. (DOI: 10.1293/tox.2016-0017; J Toxicol Pathol 2016; 29: 261-264)
\end{abstract}

Key words: alloxan, tubular necrosis, mineralization, granuloma, rat

The alloxan-induced type 1 diabetic rat is one of the most commonly used experimental animal models of diabetes. Prior to inducing a prolonged diabetic state, alloxan causes acute tubulointerstitial nephritis, consequently leading to nephrotoxicity and animal deaths ${ }^{1-3}$. There are only a few reports on severe luminal and interstitial mineralization induced by alloxan ${ }^{2}$. Herein, we report a case of granulomatous tubulointerstitial nephritis with severe luminal and interstitial mineralization in an alloxan-induced rat and describe its pathological features.

Six-week-old Wistar/Crlj male rats were purchased from Charles River Laboratories Japan, Inc., and reared in a barrier-sustained animal room maintained at a temperature of $23 \pm 2{ }^{\circ} \mathrm{C}$ and a relative humidity of $55 \pm 10 \%$ with 12-h light/dark cycles and ventilation at least 10 times/h with high-efficiency particulate air-filtered fresh air. Twelve rats were administered a single dose of alloxan $(50 \mathrm{mg} / \mathrm{kg})$ by intravenous injection at 7 weeks of age. Rats other than the case showed no apparent clinical symptoms or renal

Received: 27 February 2016, Accepted: 2 May 2016

Published online in J-STAGE: 27 May 2016

*Corresponding author: K Ozaki

(e-mail: ozaki@pharm.setsunan.ac.jp)

(C)2016 The Japanese Society of Toxicologic Pathology

This is an open-access article distributed under the terms of the Creative Commons Attribution Non-Commercial No Derivatives (by-ncnd) License $<$ http://creativecommons.org/licenses/by-nc-nd/4.0/>. histological changes except the diabetic condition, and all rats were sacrificed at 7 days after alloxan administration. One rat experienced a gradual reduction in body weight accompanied by both a reduction in food intake and urine volume following alloxan injection. Its kidneys were fixed in $10 \%$ phosphate-buffered formalin, dehydrated, and then embedded in paraffin. Sections $(4 \mu \mathrm{m}$ thick) were stained with hematoxylin and eosin, PAS reaction, and Von Kossa's method. For immunohistochemical examination, the sections were deparaffinized in xylene and rehydrated through graded ethanol series. The rehydrated sections were microwaved in $10 \mathrm{mM}$ citrate buffer ( $\mathrm{pH} \mathrm{6.0)}$ for $10 \mathrm{~min}$ at $98^{\circ} \mathrm{C}$ to retrieve the antigen. Solutions and washes were prepared between the various steps using $0.05 \mathrm{M}$ Tris buffered saline (TBS, pH 7.6) with $0.01 \%$ Tween 20 . Nonspecific endogenous peroxidase activity was blocked by exposure to $0.03 \%$ hydrogen peroxide in $100 \%$ methanol for $5 \mathrm{~min}$, and masking was conducted with $1 \%$ goat or horse normal serum in Tris buffered saline for $5 \mathrm{~min}$ at room temperature. Incubation was carried out overnight at $4{ }^{\circ} \mathrm{C}$ with anti-aquaporin 1 (AQP1) rabbit polyclonal antibody (diluted 1:500, AB2219, Millipore, Billerica, MA, USA), anti-sodium/potassium ATPase subunit alpha $1(\mathrm{Na} / \mathrm{K}$ pump) mouse monoclonal antibody (diluted 1:1,000, 05-369, Millipore) and anti-Iba1 rabbit polyclonal antibody (diluted 1:500, 019-19741, Wako Pure Chemical Industries, Osaka, Japan). These slides were subsequently rinsed with TBS plus Tween 20, treated for $30 \mathrm{~min}$ at room temperature with biotinylated secondary 
antibody (Vectastain Elite kit, PK6102, PK6101, Vector Laboratories, Burlingame, CA, USA), rinsed with TBS plus Tween 20, incubated for $30 \mathrm{~min}$ at room temperature with Vectastain Elite ABC reagent (Vectastain Elite kit, PK6102, PK6101, Vector Laboratories), rinsed with TBS plus Tween 20 , incubated in diaminobenzidine solution containing $0.01 \%$ hydrogen peroxide for the peroxidase coloring reaction, and counterstained with Mayer's hematoxylin.

Grossly, both the kidneys were enlarged. Other organs and tissues had no gross findings. Histologically, both the kidneys showed similar lesions. Many dilated and occluded tubules were segmentally observed in the cortex and outer medulla (Fig. 1). Degeneration and necrosis of tubular epithelial cells were seen along with tubular obstruction due to cell debris and mineralization (Fig. 2). Dilated regenerated tubules were lined with flattened and attenuated epithelia in basophilic cytoplasm. These tubular epithelial cells often piled up, formed small cell clusters, and protruded into the lumen. In some tubules, protruded tubular epithelial cells enveloped minerals (Fig. 3). The mineralization was confirmed as calcium salts using Von Kossa's method (Fig. 4) and was observed in the tubular lumen, subepithelium, and interstitium (Fig. 2), but apparent mineralization of the arterial wall was not seen. The mineralization beneath the tubular epithelium was often continuous from the subepithelium to the interstitium. In these lesions, the tubular basement membrane was sometimes disrupted by mineralization (Fig. 5), and multinuclear foreign-body giant cells and macrophages often infiltrated (Fig. 2). Multinuclear foreignbody giant cells were usually located around minerals, and they often contained minerals in their cytoplasm (Fig. 2). Double staining with PAS and Ibal confirmed that Ibalpositive macrophages infiltrated from the interstitium to the subepithelial mineralization area, penetrating the basal lamina (Fig. 6). Many degenerated and regenerated tubules did not have a brush border, but some dilated and degenerated tubules did. Both the $\mathrm{Na} / \mathrm{K}$ pump-positive distal tubules and AQP1-positive proximal tubules (Fig. 7) showed degenerative changes. However, severely damaged tubules did not express either AQP1 or the $\mathrm{Na} / \mathrm{K}$ pump.

The nephrotoxic effect of alloxan had been recognized long before its diabetogenic action was identified ${ }^{1-3}$. Renal changes included extensive swelling and vacuolar degeneration of tubular cells, necrosis of tubular cells, tubular dilation, and cellular infiltrates resembling granulomas in the interstitium from the third day to fourteenth day following alloxan administration ${ }^{2}$. Renal damage may lead to uremia and death. In this report, the histologic changes observed in an alloxan-induced diabetic rat resembled those in previous reports ${ }^{2}$, and they were likely due to the nephrotoxicity of alloxan.

Unlike previous reports, to the best of our knowledge, severe mineralization was not found in the rat with alloxaninduced nephrotoxicity. In the present case, mineralization of calcium salts located in the tubular lumen and beneath the tubular epithelium resulted in the formation of granulo- mas in the interstitial and tubular regions. As the continuity of mineralization between the tubule and the interstitium was apparent, it is possible that translocation of minerals from the tubular lumen to the interstitium occurred, a process that has been well demonstrated for calcium oxalate $(\mathrm{CaOx})$ crystals (crystalline nephritis) ${ }^{4-8}$. The crystals of $\mathrm{CaOx}$ generally form in the renal tubules. If crystals come in contact with renal epithelial cells, they are endocytosed and moved to lysosomes for removal or moved from the luminal to the basolateral side between the cells and the basement membrane ${ }^{4-8}$. They are subsequently transported to the renal interstitium, where macrophages eliminate them while inducing an inflammatory and foreign body reaction 4 . In our case, the features of the protruded granuloma with mineralization and the continuity of mineralization between the tubule and the interstitium resembled a granuloma with crystals in crystalline nephritis. Thus, the unique pathologic features of our case may also be caused by the translocation of minerals from the tubular lumen to the interstitium. However, it is well-known that mineralization occurs in tubules, the tubular lumen, and the interstitium of the kidney as dystrophic calcification in rats including those of the Wister strain9. In addition, although apparent mineralization of the arterial wall was not seen, metastatic calcification as a result of systemic calcium/phosphorus imbalance may occur in the kidney. Thus, the possibility that mineralization simultaneously occurred in the tubules, tubular lumen, and interstitium as a dystrophic or metastatic calcification cannot be ruled out. Further study will be needed to clarify the mechanism of mineralization.

Alloxan is a small molecule that resembles glucose, binds the GLUT-2 glucose transporter, and can enter cells via the GLUT2 glucose transporter ${ }^{10,11}$. It generates superoxide and hydroxyl radicals; since beta cells have relatively weak defenses against oxidative stress, they are especially sensitive to free radical-mediated damage by alloxan and undergo necrotic cell death within 48 hours postinjection ${ }^{12}$. The GLUT2 glucose transporter is expressed in beta cells, hepatocytes, renal tubular cells, and small intestinal epithelial cells ${ }^{12}$. This transporter of renal tubules is mainly located at the basolateral membrane of proximal tubular epithelial cells. If alloxan induced tubular damage via GLUT2, only the proximal tubule would be damaged. However, in our case, both the $\mathrm{Na} / \mathrm{K}$ pump-positive distal tubules and the AQP1-positive proximal tubules showed degenerative changes. Thus, the renal toxicity of alloxan may involve other mechanisms independent of the GLUT2 glucose transporter.

Acknowledgment: Disclosure of potential conflicts of interest: The authors declare that they have no competing interests.

Disclosure of Potential Conflicts of Interest: The authors declare that they have no competing interests. 


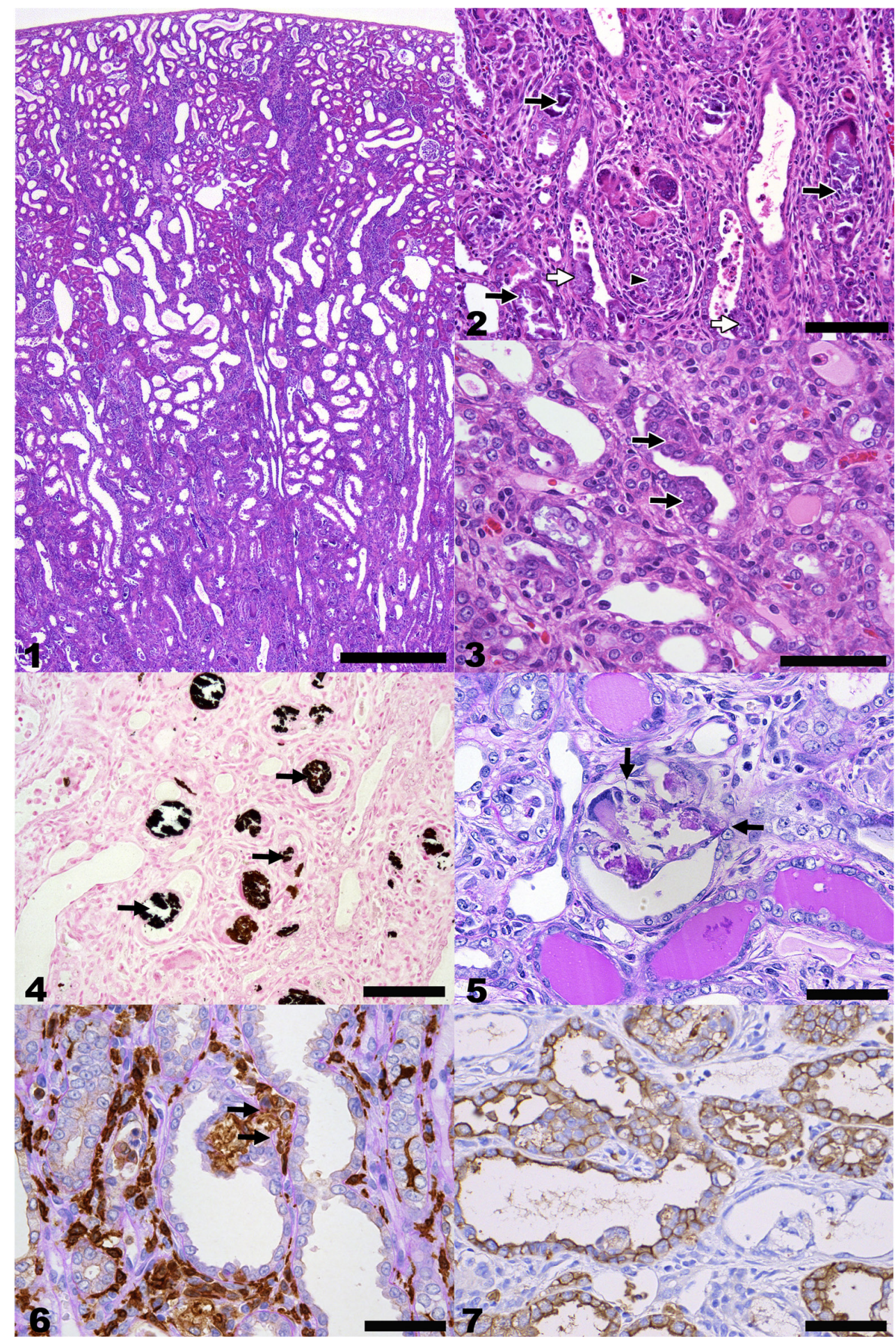

Fig. 1. Dilated and occluded tubules in the cortex and outer medulla. Bar $=500 \mu \mathrm{m}$. HE stain.

Fig. 2. Degeneration and necrosis of tubular epithelial cells are seen with tubular obstruction by cell debris and mineralization (arrows). Mineralization is observed mainly within the tubular lumen and to some extent in the subepithelium (open arrows) and interstitium (arrowhead). Infiltration of multinuclear foreign-body giant cells and fibrotic macrophages. Bar $=100 \mu \mathrm{m}$. HE stain.

Fig. 3. Protruded tubular epithelial cells envelope minerals (arrows). Bar $=100 \mu \mathrm{m}$. HE stain.

Fig. 4. Minerals are positive for Von Kossa's stain. Protruded tubular epithelial cells envelope minerals (arrows). Bar $=100 \mu \mathrm{m}$. Von Kossa's method.

Fig. 5. A tubular basement membrane (arrows) is disrupted by mineralization and foreign-body giant cells. Bar $=50 \mu \mathrm{m}$. PAS reaction .

Fig. 6. Iba-1-positive macrophages infiltrate from the interstitium into the subepithelial mineralization area, penetrating the basal lamina (arrows). Bar $=50 \mu \mathrm{m}$. PAS reaction and immunohistochemical staining for Ibal.

Fig. 7. Damaged and dilated tubules show various levels of immunopositivity for AQP-1. Bar $=50 \mu \mathrm{m}$. Immunohistochemical staining for AQP1 and hematoxylin counterstain. 


\section{References}

1. Evan AP, Mong SA, Connors BA, Aronoff GR, and Luft FC. The effect of alloxan, and alloxan-induced diabetes on the kidney. Anat Rec. 208: 33-47. 1984. [Medline] [CrossRef]

2. Vargas L, Friederici HH, and Maibenco HC. Cortical sponge kidneys induced in rats by alloxan. Diabetes. 19: 33-44. 1970. [Medline] [CrossRef]

3. Bruckmann G, and Wertheimer E. Alloxan studies; the action of alloxan homologues and related compounds. J Biol Chem. 168: 241-256. 1947. [Medline]

4. de Water R, Noordermeer C, Houtsmuller AB, Nigg AL, Stijnen T, Schröder FH, and Kok DJ. Role of macrophages in nephrolithiasis in rats: an analysis of the renal interstitium. Am J Kidney Dis. 36: 615-625. 2000. [Medline] [CrossRef]

5. Boevé ER, Ketelaars GA, Vermeij M, Cao LC, Schröder $\mathrm{FH}$, and De Bruijn WC. An ultrastructural study of experimentally induced microliths in rat proximal and distal tubules. J Urol. 149: 893-899. 1993. [Medline]

6. de Bruijn WC, Boevé ER, van Run PR, van Miert PP, Romijn JC, Verkoelen CF, Cao LC, and Schröder FH. Etiology of experimental calcium oxalate monohydrate nephrolithiasis in rats. Scanning Microsc. 8: 541-549, discussion 549-550.
1994. [Medline]

7. Lieske JC, Spargo BH, and Toback FG. Endocytosis of calcium oxalate crystals and proliferation of renal tubular epithelial cells in a patient with type 1 primary hyperoxaluria. J Urol. 148: 1517-1519. 1992. [Medline]

8. Khan SR. Calcium oxalate crystal interaction with renal tubular epithelium, mechanism of crystal adhesion and its impact on stone development. Urol Res. 23: 71-79. 1995. [Medline] [CrossRef]

9. Mann PC, Vahle J, Keenan CM, Baker JF, Bradley AE, Goodman DG, Harada T, Herbert R, Kaufmann W, Kellner $\mathrm{R}$, Nolte $\mathrm{T}$, Rittinghausen $\mathrm{S}$, and Tanaka T. International harmonization of toxicologic pathology nomenclature: an overview and review of basic principles. Toxicol Pathol. 40(Suppl): 7S-13S. 2012. [Medline] [CrossRef]

10. Elsner M, Tiedge M, Guldbakke B, Munday R, and Lenzen S. Importance of the GLUT2 glucose transporter for pancreatic beta cell toxicity of alloxan. Diabetologia. 45: 1542-1549. 2002. [Medline] [CrossRef]

11. Weaver DC, McDaniel ML, and Lacy PE. Alloxan uptake by isolated rat islets of Langerhans. Endocrinology. 102: 1847-1855. 1978. [Medline] [CrossRef]

12. Lenzen S. The mechanisms of alloxan- and streptozotocininduced diabetes. Diabetologia. 51: 216-226. 2008. [Medline] [CrossRef] 